Legislation allowing dairy farmers to treat milk fever with intravenous calcium results in more treatments and lower case fatality

Thomsen, Peter Thorup; Houe, Hans

Published in:

Veterinary Record

DOI:

10.1136/vr.102322

Publication date:

2014

Document version

Early version, also known as pre-print

Citation for published version (APA):

Thomsen, P. T., \& Houe, H. (2014). Legislation allowing dairy farmers to treat milk fever with intravenous calcium results in more treatments and lower case fatality. Veterinary Record, 174, [252].

https://doi.org/10.1136/vr.102322 


\section{Short Communication}

\section{Legislation allowing dairy farmers to treat milk fever with intravenous calcium results in more treatments and lower case fatality}

\section{P. T. Thomsen, H. Houe}

UNTIL recently, Danish dairy farmers have not been allowed to treat their own dairy cows suffering from milk fever using intravenous infusions of calcium. Such treatments could only be performed by a veterinarian. Farmers were only allowed to perform oral calcium treatments. In September 2010, a new legislation made it possible for Danish dairy farmers to use intravenous infusions of calcium to treat their own cows suffering from milk fever (Anonymous 2010). It has recently been shown that farmers with easier access to own treatment had higher intention-to-treat cases of mild clinical mastitis (Lind and others 2012). It can therefore be anticipated that the new legislation for treatment of milk fever could affect the treatment rate for this disease also.

The objectives of the present study were to evaluate whether the new possibility for the farmers themselves to treat cows suffering from milk fever has had any effect on (1) the proportion of cows treated for milk fever, (2) the number of treatments per case of milk fever and (3) the case fatality among cows treated for milk fever.

According to the new legislation, Danish farmers need to complete a course (including 1 day theory and treatment of five milk fever cases under the supervision of a veterinarian) in order to become authorised to perform treatments with intravenous calcium infusions. Additionally, the farmers have to participate in a herd health programme with weekly routine herd visits by a veterinarian. Participation in the course and the subsequent possibility of performing intravenous treatments are voluntary for farmers. As part of the authorisation, the farmer is required to record all intravenous treatments and report them to the Danish Cattle Database. All milk fever treatments performed by veterinarians are also recorded and reported to the Danish Cattle Database. Farmers are only allowed to treat uncomplicated cases of milk fever (based on a decision tree including information about typical clinical signs of milk fever, such as paresis paralysis, low body temperature, dry muzzle and reduced appetite associated with calving). Complicated and atypical cases (eg, a para-

Veterinary Record (2014)

P. T. Thomsen, DVM, Ph.D., Dipl. ECBHM,

Department of Animal Science, Aarhus University, P. 0. Box 50, Tjele DK-8830,

Denmark

H. Houe, DVM, Ph.D., DVSc, Dipl.

ECBHM,

Department of Large Animal

Sciences, University of Copenhagen, doi: $10.1136 /$ vi.102322

Grønnegårdsvej 8 ,

Frederiksberg CDK-1870

Denmark

E-mail for correspondence:

PeterT.Thomsen@agrsci.dk

Provenance: not commissioned; extemally peer reviewed

Accepted 3 February 2014 lysed cow with increased body temperature or visible changes in the milk) must be treated by a veterinarian, even though the farmer is authorised to perform treatments. By November 2012, 867 herds (approximately 25 per cent of all Danish dairy herds) were authorised to perform intravenous treatments for milk fever. All these herds were included in the study.

We compared (1) the incidence risk of milk fever, (2) the mean number of treatments per milk fever case and (3) the case fatality, between two periods: period A from one year before the date of authorisation up to and including the date of authorisation of the individual herd (termed 'before' in the remaining text), and period B from the date of authorisation until one year after the date of authorisation of the individual herd (termed 'after' in the remaining text). Before the date of authorisation, all intravenous milk fever treatments were performed by a veterinarian. After the date of authorisation, intravenous milk fever treatments could be performed either by the farmer or by the veterinarian.

Of the 867 herds originally included in the study, the owners of 23 herds chose to stop treating cows suffering from milk fever themselves within the first year after the date of authorisation. These herds were excluded from the study. Information about individual calvings (herd/cow identity and date), intravenous milk fever treatments (herd/ cow identity, date and who performed the treatment), and cases of unassisted death or euthanasia at the farm (herd/cow identity and date) were extracted from the Danish Cattle Database on December 14,2012. A total of 153 herds which had been authorised to perform treatments less than one year before this date were excluded from the analysis in order to exclude herds with an 'after' period of less than one year. The final dataset for analysis thus included 691 herds each with full information for 365 days 'before' and 365 days 'after' the date of authorisation. This way, any effect of season was accounted for as both periods in each herd included all seasons of a year.

The incidence risk of milk fever was calculated as the number of cases of milk fever divided by the number of calvings for each period ('before' and 'after'). A cow treated intravenously for milk fever counted as one case irrespective of the number of treatments performed in relation to the individual calving. Only milk fever treatments performed from 14 days before calving to 14 days after calving were included. The mean number of treatments per milk fever case was calculated as the total number of treatments for milk fever for each period divided by the number of milk fever cases for the period. Case fatality was calculated as the percentage of cows dying unassisted or being euthanased on the farm of the cows treated for milk fever. Only cows dying or being euthanased within 30 days after calving were included. A total of nine cows treated for milk fever and calving within the last 30 days before the extraction of data from the Danish Cattle Database were excluded. The statistical significance of changes in incidence risk of milk fever, mean number of treatments per milk fever case, and case fatality before and after authorisation was evaluated using a Wilcoxon signed rank test (PROC UNIVARIATE, SAS V.9.2) taking the paired nature of the data into account.

In the period 'before' authorisation, 167,301 calvings were recorded in the 691 herds. The number of milk fever cases treated with intravenous calcium was 5342 - resulting in an incidence risk of 3.19 per cent-and the total number of treatments (= intravenous calcium infusions) for milk fever was 6781 . The mean number of treatments per milk fever case was 1.27. In the period 'after' authorisation, 177,136 calvings were recorded in the 691 herds. The number of milk fever cases was 11,313-equivalent to an incidence risk of 6.39 per cent-and the total number of treatments for milk fever was 13,198. The mean number of treatments per milk fever case was 1.17. The distribution of number of treatments per case is illustrated in Fig 1. 'Before' authorisation, 20.1 per cent of all cows with milk fever had more than one intravenous treatment; the corresponding figure was 13.3 per cent 'after' authorisation. Case fatality the first 30 days after calving decreased from 11.81 per cent 'before' to 7.79 per cent 'after' 


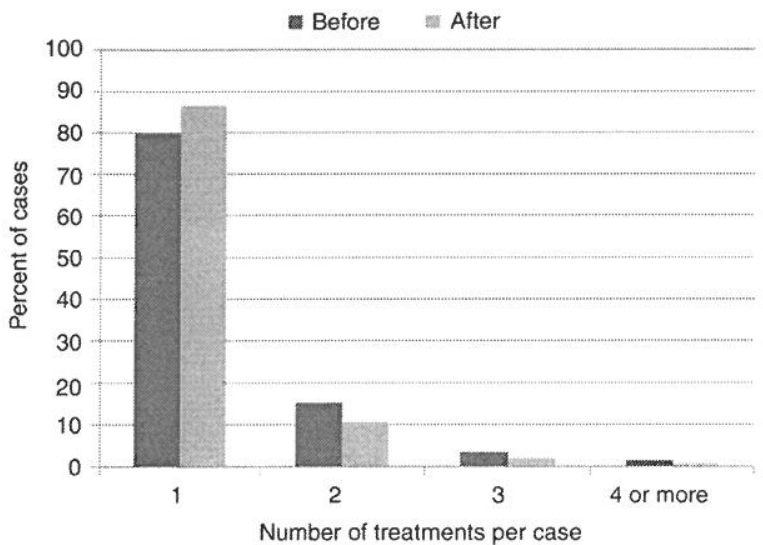

FIG 1: Distribution of the number of treatments per milk fever case 'before' and 'after' Danish dairy farmers had been authorised to treat their own cows suffering from milk fever using intravenous infusions of calcium

authorisation. All differences were highly significant (incidence risk: $\mathrm{P}<0.0001$; number of treatments per case: $\mathrm{P}<0.0001$; case fatality: $\mathrm{P}=0.0004)$.

The incidence risk of intravenous treatments for milk fever was twice as high 'after' ( 6.4 per cent) compared to 'before' ( 3.2 per cent) the farmers started to treat milk fever. The most likely explanation for this increase is that the threshold for treatment had changed. Having the possibility to treat cows with milk fever themselves means a dramatic reduction in the cost of treatment-especially at night and during weekends. The estimated average costs of a milk fever treatment performed by a veterinarian is approximately 400 DKK (700 DKK during nights and weekends) compared to less than 100 DKK for a treatment performed by the farmer. This is likely to have caused farmers to generally lower the threshold for treatment and treat more cows with milder symptoms compared to the 'before' situation. The fact that the mean number of treatments per case was significantly lower 'after' than 'before' also supports this. It is there- fore likely that many of the cases 'after' have been milder. This may explain why the case fatality was significantly lower ' $a f t e r$ ' ( 7.8 per cent) compared to 'before' (11.8 per cent) the farmers started performing treatments. The study design doesn't allow for any inferences regarding whether deaths in cows treated for milk fever were a direct or indirect consequence of the milk fever or the treatment, or were caused by other independent factors.

'Before' farmers started performing treatments, all treatments were performed by a veterinarian. 'After' farmers started performing treatments, 94.1 per cent of treatments were performed by the farmer and 5.9 per cent by a veterinarian. The cases treated by a veterinarian 'after' authorisation were typically complicated cases which the farmers were not allowed to treat themselves. Excluding these cases would have introduced a selection bias as it would have meant that complicated and uncomplicated cases 'before' (all veterinary treated) would have been compared to only uncomplicated cases 'after' (farmer treated). Therefore, a minority of cases treated by a veterinarian in the 'after' period were included in the study. The mean size of the herds in the study was larger (approximately 250 cows) than the mean herd size in Denmark (approximately 160 cows). However, as the study design compared treatments in each herd before and after authorisation, this does not affect the interpretation of the results.

In conclusion, this study demonstrated that allowing dairy farmers to treat their own cows suffering from milk fever resulted in significantly more treatments - most likely due to a lowered threshold for treatment among farmers-and a significantly lower case fatality.

\section{References}

ANONYMOUS (2010). Ministerial order no. 1024, Danish Ministry of Food, Agriculture and Fisheries. www.retsinformation.dk. Accessed November 28, 2013 LIND, A., THOMSEN, P. T., RINTAKOSKI, S., ESPEVEDT, M. N., WOLFF, C. \& HOUE, H. (2012) The association between farmers' participation in herd health programmes and their behaviour concening treatment of mild clinical mastitis. Acia Veterinaria Scandinavica 54,62 


\title{
Veterinary \\ Legislation allowing dairy farmers to treat milk fever with intravenous calcium results in more treatments and lower case fatality
}

\author{
P. T. Thomsen and H. Houe
}

Veterinary Record published online February 25, 2014

doi: $10.1136 / v r .102322$

Updated information and services can be found at:

http://veterinaryrecord.bmj.com/content/early/2014/02/25/vr.102322.full.html

\begin{abstract}
These include:
References This article cites 1 articles

http://veterinaryrecord.bmj.com/content/early/2014/02/25/vr.102322.full.html\#ref-list-1

$\mathbf{P}<\mathbf{P} \quad$ Published online February 25, 2014 in advance of the print journal.

Email alerting Receive free email alerts when new articles cite this article. Sign up in service the box at the top right corner of the online article.

Notes

Advance online articles have been peer reviewed, accepted for publication, edited and typeset, but have not not yet appeared in the paper journal. Advance online articles are citable and establish publication priority; they are indexed by PubMed from initial publication. Citations to Advance online articles must include the digital object identifier (DOIs) and date of initial publication.
\end{abstract}

To request permissions go to:

http://group.bmj.com/group/rights-licensing/permissions

To order reprints go to:

http:/ljournals.bmj.com/cgi/reprintform

To subscribe to BMJ go to:

http://group.bmj.com/subscribe/ 